\title{
Lactone Compound
}

National Cancer Institute

\section{Source}

National Cancer Institute. Lactone Compound. NCI Thesaurus. Code C606.

Cyclic esters of hydroxy carboxylic acids, containing a 1-oxacycloalkan-2-one structure, or analogues having unsaturation or heteroatoms replacing one or more carbon atoms of the ring (IUPAC). 